\title{
Survival of patients with ovarian cancer in central and northern Denmark, 1998-2009
}

This article was published in the following Dove Press journal:

Clinical Epidemiology

19 July 2011

Number of times this article has been viewed

\author{
Anne Fia Grann' \\ Mette Nørgaard' \\ Jan Blaakær ${ }^{2}$ \\ Erik Søgaard-Andersen ${ }^{3}$ \\ Jacob Bonde Jacobsen' \\ 'Department of Clinical Epidemiology, \\ Aarhus University Hospital, \\ Aarhus, Denmark; ${ }^{2}$ Department of \\ Gynaecology and Obstetrics, Aarhus \\ University Hospital, Aarhus, Denmark; \\ ${ }^{3}$ Department of Gynaecology and \\ Obstetrics, Aalborg University \\ Hospital, Aalborg, Denmark
}

Correspondence: Anne Fia Grann Department of Clinical Epidemiology, Clinical Institute, Aarhus University Hospital, Olof Palmes Allé 43-45, DK-8200 Aarhus N, Denmark Tel +4589424800

Fax +4589424801

Email afg@dce.au.dk
Objective: To examine time trends of survival and mortality of ovarian cancer in the central and northern Denmark regions during the period 1998-2009.

Study design and setting: We conducted a cohort study including women recorded with a first-time diagnosis of ovarian cancer in the Danish National Registry of Patients (DNRP) between 1998 and 2009. Patients were followed for survival through the Danish Civil Registration System. We determined survival stratified by age, and used Cox proportional hazard regression analyses to obtain mortality rate ratios (MRRs) to assess changes over time.

Results: We found no improvement in overall ovarian cancer survival between 1998 and 2009. One-year survival was 71\% in 1998-2000 and 68\% in 2007-2009. Three-year survival declined from $48 \%$ in $1998-2000$ to $46 \%$ in 2007-2009 (predicted), and 5-year survival declined from $40 \%$ in 1998-2000 to 37\% in 2007-2009 (predicted). Compared with the period 1998-2000, the age-adjusted 1-year MRR was 1.05 (95\% confidence interval CI: 0.86-1.28) for the period 2007-2009, and the predicted age-adjusted 3- and 5-year MRRs were 0.96 (95\% CI: 0.83-1.12) and 0.99 (95\% CI: 0.86-1.14), respectively. Results are not adjusted for tumor stage as this information was not available. We also observed a decline in the annual number of incident ovarian cancer patients during the study period, most pronounced in the youngest age group.

Conclusion: The survival of ovarian cancer patients did not improve during the study period. This lack of improvement contrasts with the national cancer strategies implemented during this last decade, focusing on improving the survival of ovarian cancer patients.

Keywords: ovarian neoplasm, outcome research, MRR, mortality rate ratio

\section{Introduction}

Ovarian cancer is the eighth most commonly diagnosed cancer in Danish women, with 577 new cases diagnosed in 2009, corresponding to an incidence rate of 19 per 100,000 women per year. ${ }^{1}$ Lack of both clearly defined symptoms and knowledge of the natural history of the tumor makes screening and early diagnosis of ovarian cancer difficult, resulting in detection at more advanced stages with poor prognosis. A Nordic study following ovarian cancer patients diagnosed in 1964 to 2003 to end of $2006^{2}$ found declines in ovarian cancer incidence and mortality in all Nordic countries. Throughout the period, however, survival remained lower and mortality rates higher in Denmark than in the other Nordic countries. In patients diagnosed in 1999 to 2003, 5-year relative survival was 33\% in Denmark compared with $40 \%$ in the other Nordic countries. This is consistent with previous studies showing lower survival in Danish ovarian cancer patients compared with patients in other European countries. ${ }^{3-5}$ A recent study by Coleman et $\mathrm{al}^{6}$ identified 121,059 patients diagnosed with primary 
ovarian cancer in six different countries (Australia, Canada, Norway, Sweden, UK, and Denmark) during 1995-2007 through population-based cancer registries. Danish ovarian cancer patients had lower relative 1- and 5-year survival than patients from all other countries except the UK. So far, the reasons for this poorer survival of Danish ovarian cancer patients remain unknown.

Primary radically intended surgery and postoperative chemotherapy is the main treatment for ovarian cancer. ${ }^{7,8}$ Until 1998, surgery of gynecological cancer in Denmark took place at general departments of gynecology and obstetrics (over 40 different departments). ${ }^{9}$ In 2000 and 2005, the first and second Danish Cancer Control Plans were initiated. ${ }^{10}$ The launched initiatives focused on reduction of diagnostic delay, treatment restricted to specialized centers, and establishment of multidisciplinary cancer groups.

Because of the poor prognosis of ovarian cancer in Denmark, it is important to monitor survival as an indicator of quality of treatment. We therefore used population-based hospital discharge registries to examine changes in mortality and survival of ovarian cancer patients diagnosed between 1998 and 2009. We thereby extended a previous study from our regions, covering ovarian cancer survival in the period 1985-2004. ${ }^{11}$

\section{Materials and methods}

We conducted this study in the central and the northern Denmark regions, with a combined population of 1.8 million persons. The National Health Service provides tax-supported health care for all inhabitants of Denmark, guaranteeing free access to hospitals. Virtually no ovarian cancer patients were treated in private hospitals during the study period.

\section{Identification of ovarian cancer patients} Hospital discharge registries

Through the Danish National Registry of Patients (DNRP), we identified all patients who had a first-time hospitalization with ovarian cancer in the period January 1, 1998 through December 31, 2009. The DNRP contains information about all admissions from nonpsychiatric hospitals in Denmark since $1977 .{ }^{12}$ Outpatient and emergency room visits at hospitals have been included since 1995 . This registry includes information on civil registration number, dates of admission and discharge, surgical procedure(s) performed, and up to 20 diagnoses from each hospital contact. Diagnoses have been classified according to the International Classification of Diseases 8th edition (ICD-8) until the end of 1993 and 10th edition (ICD-10) thereafter. Surgical procedures have been classified according to a Danish classification system until the end of 1995 and according to a Danish version of the Nordic Classification of Surgical Procedures (NCSP) thereafter.

The ICD-10 codes used to identify ovarian cancer were C56.x and the ICD-8 codes used were 183.00-183.09.

\section{The Danish Civil Registration System}

Since 1968, the Central Office of Civil Registration has assigned a unique 10-digit personal identification number to all Danish citizens. ${ }^{13}$ This number, unique to each Danish resident, is used in all Danish registries, allowing unambiguous individual-level data linkage. From the Civil Registration System we also obtained information on vital status (dead or alive), date of death, and residence for all cancer patients.

\section{Statistical analysis}

\section{Survival}

We followed each patient from date of cancer diagnosis until emigration, death, or June 25, 2010, whichever came first. To visualize crude survival we constructed KaplanMeier curves stratified according to period of diagnosis (1998-2000, 2001-2003, 2004-2006, and 2007-2009). We estimated 1-, 3-, and 5-year survival. In the latter periods, we estimated 3- and 5-year survival using a hybrid analysis in which survival was estimated using the survival experience of patients in the previous periods. ${ }^{14}$

We used Spearmans' rank correlation to test for trend in the age distribution of the incident ovarian cancer cases.

\section{Mortality}

To compare mortality over time we used Cox proportional hazards regression analysis, with 1998-2000 as the reference period to estimate 1-, 3-, and 5-year mortality rate ratios (MRRs) and corresponding 95\% confidence intervals (CIs), adjusting for age group. The survival was estimated within three age strata: 15-49 years, 50-69 years, and 70+.

Analyses were performed using SAS version 9.2 (SAS Institute Inc, Cary, NC).

\section{Results}

We identified a total of 2541 women who were diagnosed with ovarian cancer for the first time between 1998 and 2009.

\section{Age characteristics of ovarian cancer patients}

The median age was 63 (range 15-103) years over all time periods. The age distributions for the four time periods are 
Table I Number of women with a first-time diagnosis of ovarian cancer in three age groups (1998-2009)

\begin{tabular}{lllll}
\hline Age group & \multicolumn{4}{l}{ Year of diagnosis } \\
\cline { 2 - 5 } & $\mathbf{1 9 9 8 - 2 0 0 0}$ & $\mathbf{2 0 0 I - 2 0 0 3}$ & $\mathbf{2 0 0 4 - 2 0 0 6}$ & $\mathbf{2 0 0 7 - 2 0 0 9}$ \\
\hline 15-49 years & $135(20 \%)$ & $134(21 \%)$ & $85(14 \%)$ & $64(10 \%)$ \\
$50-69$ years & $298(45 \%)$ & $304(47 \%)$ & $329(53 \%)$ & $310(50 \%)$ \\
$70+$ & $231(35 \%)$ & $206(32 \%)$ & $203(33 \%)$ & $242(39 \%)$ \\
\hline
\end{tabular}

presented in Table 1 . The prevalence of women younger than 50 years of age decreased from $20 \%$ to $10 \%$ during the study period (test for trend, $P<0.001$ ). During the study period, the absolute number of women diagnosed with ovarian cancer fell from 664 patients in 1998-2000 to 616 in 2007-2009.

\section{Survival}

The overall survival curves for the four periods showed only small changes in survival over the years (Figure 1). One-year survival decreased from $71 \%$ to $68 \%$ during the period 1998-2009. This corresponded to an age-adjusted MRR of 1.05 (95\% CI $0.86-1.28)$. The predicted 3- and 5-year survival for women diagnosed in 2007-2009 were 46\% and $37 \%$, respectively, which was also a decrease in survival during the period (Table 2). The 3- and 5-year MRRs for 2007-2009 were predicted to be 0.96 (95\% CI 0.83-1.12) and 0.99 (95\% CI 0.86-1.14), respectively, compared with 1998-2000.

For all three age groups, 1-year survival remained virtually unchanged throughout the study period. For the youngest women (aged 15-49 years), the 1-year survival was $92 \%$. For women aged 50-69 years and 70 years or older, 1-year survival was $79 \%$ in $1998-2000$ and $79 \%$ in 2007-2009, and 49\% and 48\%, respectively.

A similar pattern was seen for 3- and 5-year survival (Table 3).

\section{Discussion}

In this population-based follow-up study, we found that the survival after ovarian cancer diagnosis remained almost unchanged during the period 1998-2009. Not surprisingly, the youngest age group had better survival than the older age groups, but within each age group, survival was almost unchanged over the years.

Our data thus extend findings from four previous Danish studies. Three studies, based on data from the Danish Cancer Registry, found improved 5-year survival over the period 1943-1987 (22.3\% versus $30.4 \%)^{15}$ but no improvement in survival between 1973 and 1978 and between 1981 and $1986,{ }^{16}$ and only a slight increase in survival from 1978 to 2002. ${ }^{17}$ A fourth Danish study, based on hospital discharge registries, similarly found a 5 -year survival of $30 \%$ in the period 1985-1989, with a 5-year adjusted MRR of 0.8 (95\% CI $0.72-0.90)$ from 1985 to $2004 .{ }^{11}$ Still, the overall improvement in ovarian cancer survival during the last decades has been limited.

Our study was large and included all ovarian cancer patients from a well defined area covering approximately $30 \%$ of the Danish population. We accomplished complete vital status follow-up by using the Civil Registry System.

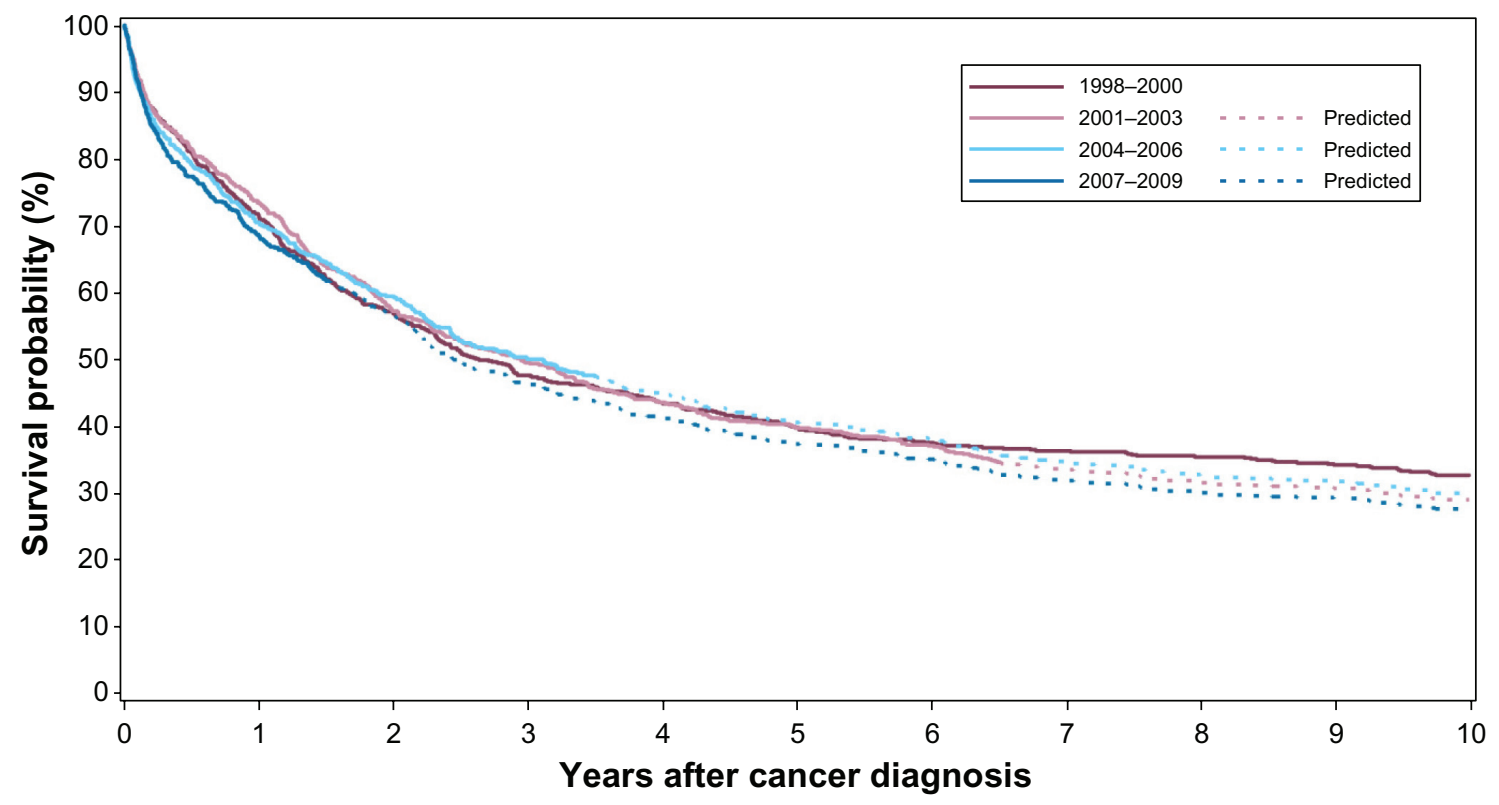

Figure I Survival of ovarian cancer patients in four time periods. 
Table 2 One-, 3-, and 5-year survival and MRRs, with the period 1998-2000 as a reference

\begin{tabular}{|c|c|c|c|c|}
\hline & \multicolumn{4}{|c|}{ Year of diagnosis } \\
\hline & $1998-2000$ & $200 I-2003$ & 2004-2006 & 2007-2009 \\
\hline Number of cancer patients & 664 & 644 & 617 & 616 \\
\hline Median age (years) & 63 & 61 & 64 & 66 \\
\hline \multicolumn{5}{|l|}{ I year } \\
\hline Survival & $71 \%(68 \%-74 \%)$ & $73 \%(70 \%-77 \%)$ & $71 \%(67 \%-74 \%)$ & $68 \%(64 \%-71 \%)$ \\
\hline MRR & I (reference) & $0.92(0.74-1.12)$ & $1.04(0.85-1.27)$ & $\mathrm{I} .15(0.94-1.40)$ \\
\hline$M_{R R}{ }^{a}$ & I (reference) & $0.95(0.77-1.17)$ & $1.04(0.85-1.27)$ & $1.05(0.86-1.28)$ \\
\hline \multicolumn{5}{|l|}{3 year } \\
\hline Survival & $48 \%(44 \%-51 \%)$ & $50 \%(46 \%-53 \%)$ & $50 \%(46 \%-54 \%)$ & $46 \%(42 \%-50 \%)^{\mathrm{b}}$ \\
\hline MRR & I (reference) & $0.95(0.8 \mathrm{I}-1.10)$ & $0.95(0.8 I-I . I I)$ & $1.05(0.90-1.22)^{\mathrm{b}}$ \\
\hline$M R R^{a}$ & I (reference) & $0.96(0.83-1.12)$ & $0.91(0.78-1.06)$ & $0.96(0.83-1.12)^{\mathrm{b}}$ \\
\hline \multicolumn{5}{|l|}{5 year } \\
\hline Survival & $40 \%(36 \%-44 \%)$ & $40 \%(36 \%-44 \%)$ & $41 \%(37 \%-44 \%)^{b}$ & $37 \%(34 \%-41 \%)^{b}$ \\
\hline MRR & I (reference) & $0.99(0.86-1.13)$ & $0.98(0.85-1.13)^{\mathrm{b}}$ & $1.07(0.93-1.23)^{\mathrm{b}}$ \\
\hline $\mathrm{MRR}^{\mathrm{a}}$ & I (reference) & $1.00(0.87-1.15)$ & $0.94(0.82-1.08)^{\mathrm{b}}$ & $0.99(0.86-1.14)^{b}$ \\
\hline
\end{tabular}

Notes: Estimates are presented with 95\% confidence intervals; adjusted for age; bredicted values.

Abbreviation: MRR, mortality rate ratio.

Data on cancer in Denmark are usually extracted from the nationwide Danish Cancer Registry because of the high completeness and accuracy of data in this registry. ${ }^{18,19}$ However, use of data from the Cancer Registry would not allow us to compute updated estimates from the most recent calendar years. Thus, data from the Cancer Registry are not optimal for an ongoing quality assessment of conceivable recent improvements in ovarian cancer treatment. Patient registries may, however, be affected by some degree of misclassification of ovarian cancer diagnoses. Malignant ovarian tumors include invasive tumors and borderline tumors. The ovarian cancer diagnoses (including borderline tumors) have previously been validated by comparing data from the hospital registry with data from the Danish Cancer
Registry. ${ }^{20}$ Ovarian cancer diagnoses had a completeness of $96 \%$ in the hospital discharge registry, and the positive predictive value was $87 \%$. Before 2001, the DNPR comprised no specific code for borderline tumors, and these could therefore not be separated from invasive tumors. In a previous Danish study by Tetsche et al, borderline tumors comprised $18 \%$ of ovarian cancers registered during 1994-2003. ${ }^{20}$ Patients with borderline tumors have a 5-year survival of $86 \%,{ }^{21}$ which is far better than that for patients with invasive disease. When interpreting our results from before 2001, it is therefore important to be aware that inclusion of borderline tumors will inflate the survival estimates compared with estimates based purely on invasive tumors, and inclusion of borderline tumors in the first part of our

Table 3 One-, 3-, and 5-year cumulative survival for ovarian cancer patients in three different age groups

\begin{tabular}{|c|c|c|c|c|}
\hline \multirow[t]{2}{*}{ Age (years) } & \multicolumn{4}{|c|}{ Year of diagnosis } \\
\hline & $1998-2000$ & $200 I-2003$ & 2004-2006 & 2007-2009 \\
\hline \multicolumn{5}{|l|}{$15-49$} \\
\hline Number of cancer patients & 135 & 134 & 85 & 64 \\
\hline I-year survival & $92 \%(86 \%-95 \%)$ & $92 \%(86 \%-95 \%)$ & $92 \%(84 \%-96 \%)$ & $92 \%(82 \%-97 \%)$ \\
\hline 3-year survival & $78 \%(70 \%-84 \%)$ & $79 \%(71 \%-85 \%)$ & $85 \%(75 \%-91 \%)$ & $80 \%(69 \%-87 \%)^{a}$ \\
\hline 5-year survival & $71 \%(62 \%-78 \%)$ & $71 \%(62 \%-78 \%)$ & $72 \%(61 \%-80 \%)^{\mathrm{a}}$ & $69 \%(57 \%-78 \%)^{a}$ \\
\hline \multicolumn{5}{|l|}{$50-69$} \\
\hline Number of cancer patients & 298 & 304 & 329 & 310 \\
\hline I-year survival & $79 \%(74 \%-83 \%)$ & $79 \%(74 \%-83 \%)$ & $78 \%(73 \%-82 \%)$ & $79 \%(73 \%-83 \%)$ \\
\hline 3-year survival & $52 \%(46 \%-58 \%)$ & $51 \%(45 \%-56 \%)$ & $53 \%(48 \%-59 \%)$ & $52 \%(47 \%-58 \%)^{a}$ \\
\hline 5-year survival & $43 \%(37 \%-48 \%)$ & $41 \%(36 \%-47 \%)$ & $44 \%(38 \%-49 \%)^{\mathrm{a}}$ & $43 \%(37 \%-48 \%)^{a}$ \\
\hline \multicolumn{5}{|l|}{$70+$} \\
\hline Number of cancer patients & 231 & 206 & 203 & 242 \\
\hline I-year survival & $49 \%(43 \%-56 \%)$ & $53 \%(46 \%-60 \%)$ & $50 \%(43 \%-57 \%)$ & $48 \%(41 \%-54 \%)$ \\
\hline 3-year survival & $24 \%(19 \%-30 \%)$ & $28 \%(22 \%-34 \%)$ & $30 \%(24 \%-36 \%)$ & $28 \%(22 \%-34 \%)^{a}$ \\
\hline 5-year survival & $18 \%(13 \%-23 \%)$ & $17 \%(12 \%-22 \%)$ & $22 \%(17 \%-28 \%)^{\mathrm{a}}$ & $20 \%(15 \%-26 \%)^{a}$ \\
\hline
\end{tabular}

Notes: Estimates are presented with $95 \%$ confidence intervals in parentheses; ${ }^{a}$ predicted values. 
study period could thus mask a potential survival benefit in patients with invasive tumors. We observed a decline in the absolute number of patients with an ovarian cancer diagnosis after 2000, which is consistent with inclusion of some borderline tumors before then.

However, factors, not related to the health care system, can also influence survival data on ovarian cancer patients. ${ }^{22}$ The outcome of ovarian cancer may be influenced by factors such as aggressiveness of the tumor as it progresses along its clinical course, presence of other diseases (comorbidity), quality and accessibility/availability of diagnostic tests, and organization of health system. ${ }^{23}$ Tumor stage at diagnosis has been identified as an important prognostic factor. ${ }^{15}$ Unfortunately, we had no information about tumor stage in our study, but during our study period, increasing use of, and better access to, diagnostic ultrasound, magnetic resonance, and computed tomography scanning may have resulted in earlier diagnosis, but these methods are implemented only when patients present with symptoms, and do not serve as a screening method contributing significantly to diagnosis at an earlier disease stage.

The impact of comorbid conditions on ovarian cancer survival has been investigated in several studies, ${ }^{24-26}$ and decreased survival has been found to be associated with presence of comorbidity. Still, we do not expect increasing prevalence of comorbidity among ovarian cancer patients to entirely explain our lack of improvement in survival. In 2000 and 2005, the first and second Danish Cancer Control Plans were initiated. ${ }^{10}$ The launched initiatives focused on reduction of diagnostic delay and establishment of multidisciplinary cancer groups. During our study period, the surgical treatment of ovarian cancer in Denmark has been centralized. ${ }^{9}$ In 2008 , the number of departments treating stage III and IV ovarian cancer was reduced to six highvolume departments. The National Board of Health recommends further reduction to four high-volume departments. ${ }^{9}$ The proposed centralization has been implemented only in the recent years, accomplished by more extensive, radical surgery. In our study, these initiatives have not yet resulted in better survival of ovarian cancer patients living in central and northern Denmark.

\section{Conclusion}

The survival of ovarian cancer patients has not improved during the study period. This lack of improvement contrasts with the national cancer strategies implemented during this last decade focusing on improving the survival of ovarian cancer patients.

\section{Financial support}

The study received financial support from the Karen Elise Jensen Foundation, Department of Clinical Epidemiology's Research Foundation, and the Regional Clinical Epidemiological Monitoring Initiative for the central and northern Denmark regions.

\section{Disclosure}

The authors report no conflicts of interest in this work.

\section{References}

1. Cancer registret 2009. http://www.sst.dk/publ/Publ2010/DOKU/ Registre/Cancerregisteret2009.pdf.2011. Accessed May 18, 2011.

2. Klint A, Tryggvadottir L, Bray F, et al. Trends in the survival of patients diagnosed with cancer in female genital organs in the Nordic countries 1964-2003 followed up to the end of 2006. Acta Oncol. 2010; 49:632-643.

3. Bray F, Loos AH, Tognazzo S, et al. Ovarian cancer in Europe: crosssectional trends in incidence and mortality in 28 countries, 1953-2000. Int J Cancer. 2005;113:977-990.

4. Gatta G, Lasota MB, Verdecchia A. Survival of European women with gynaecological tumours, during the period 1978-1989. Eur J Cancer. 1998;34:2218-2225.

5. La VC, Bosetti C, Lucchini F, et al. Cancer mortality in Europe, 2000-2004, and an overview of trends since 1975. Ann Oncol. 2010; 21:1323-1360.

6. Coleman MP, Forman D, Bryant H, et al. Cancer survival in Australia, Canada, Denmark, Norway, Sweden, and the UK, 1995-2007 (the International Cancer Benchmarking Partnership): an analysis of population-based cancer registry data. Lancet. 2011;377:127-138.

7. Brun JL, Feyler A, Chene G, et al. Long-term results and prognostic factors in patients with epithelial ovarian cancer. Gynecol Oncol. 2000; 78:21-27.

8. Fujiwara K, Sakuragi N, Suzuki S, et al. First-line intraperitoneal carboplatin-based chemotherapy for 165 patients with epithelial ovarian carcinoma: results of long-term follow-up. Gynecol Oncol. 2003;90: $637-643$.

9. Ottesen B, Iversen MG, Kehlet H. Surgical treatment for ovarian cancer in Denmark 2004-2007. Ugeskr Laeger. 2009;171:217-220.

10. Storm HH, Gislum M, Engholm G. Cancer survival before and after initiating the Danish Cancer Control plan. Ugeskr Laeger. 2008; 170:3065-3069.

11. Tetsche MS, Norgaard M, Jacobsen J, et al. Improved survival of patients with ovarian cancer in Northern Denmark, 1985-2004. Eur J Gynaecol Oncol. 2006;27:119-122.

12. Andersen TF, Madsen M, Jorgensen J, et al. The Danish National Hospital Register. A valuable source of data for modern health sciences. Dan Med Bull. 1999;46:263-268.

13. Pedersen CB, Gotzsche H, Moller JO, et al. The Danish Civil Registration System. A cohort of eight million persons. Dan Med Bull. 2006;53:441-449.

14. Brenner H, Rachet B. Hybrid analysis for up-to-date long-term survival rates in cancer registries with delayed recording of incident cases. Eur $J$ Cancer. 2004;40:2494-2501.

15. Kjaer SK, Storm HH. Survival of Danish cancer patients 1943-1987. Female genital organs. APMIS Suppl. 1993;33:107-121.

16. Bertelsen K, Kruhoffer A. What have we achieved in ovarian cancer? A comparison of survivals and resources in two different periods. Int J Gynecol Cancer. 1995;5:148-155.

17. Hannibal CG, Cortes R, Engholm G, et al. Survival of ovarian cancer patients in Denmark: excess mortality risk analysis of five-year relative survival in the period 1978-2002. Acta Obstet Gynecol Scand. 2008; 87:1353-1360. 
18. Storm HH. Completeness of cancer registration in Denmark 1943-1966 and efficacy of record linkage procedures. Int J Epidemiol. 1988; $17: 44-49$

19. Storm HH, Michelsen EV, Clemmensen IH, et al. The Danish Cancer Registry - history, content, quality and use. Dan Med Bull. 1997; 44:535-539.

20. Tetsche MS, Norgaard M, Skriver MV, et al. Accuracy of ovarian cancer ICD-10 diagnosis in a Danish population-based hospital discharge registry. Eur J Gynaecol Oncol. 2005;26:266-270.

21. Menzin AW, Gal D, Lovecchio JL. Contemporary surgical management of borderline ovarian tumors: a survey of the Society of Gynecologic Oncologists. Gynecol Oncol. 2000;78:7-9.

22. Autier P, Boniol M. Caution needed for country-specific cancer survival. Lancet. 2011;377:99-101.
23. Sackett DL, Haynes RB, Guyatt GH, et al. Clinical Epidemiology, a Basic Science for Clinical Medicine. 2nd ed. Boston: Lippincott Williams \& Wilkins; 1991:305-334.

24. Du BA, Rochon J, Lamparter C, et al. Pattern of care and impact of participation in clinical studies on the outcome in ovarian cancer. Int J Gynecol Cancer. 2005;15:183-191.

25. O’Malley CD, Cress RD, Campleman SL, et al. Survival of Californian women with epithelial ovarian cancer, 1994-1996: a population-based study. Gynecol Oncol. 2003;91:608-615.

26. Tetsche MS, Norgaard M, Jacobsen J, et al. Comorbidity and ovarian cancer survival in Denmark, 1995-2005: a population-based cohort study. Int J Gynecol Cancer. 2008;18:421-427.
Clinical Epidemiology

\section{Publish your work in this journal}

Clinical Epidemiology is an international, peer-reviewed, open access journal focusing on disease and drug epidemiology, identification of risk factors and screening procedures to develop optimal preventative initiatives and programs. Specific topics include: diagnosis, prognosis, treatment, screening, prevention, risk factor modification, systematic

Submit your manuscript here: http://www.dovepress.com/clinical-epidemiology-journal

\section{Dovepress}

reviews, risk \& safety of medical interventions, epidemiology \& biostatical methods, evaluation of guidelines, translational medicine, health policies \& economic evaluations. The manuscript management system is completely online and includes a very quick and fair peer-review system, which is all easy to use. 